\title{
THE EFFECT OF INDUCED HYPOTENSION AND TISSUE TRAUMA ON RENAL FUNCTION IN SCOLIOSIS SURGERY
}

\author{
P. B. RYlance, F. CARLI, S. E. MCARTHUR, A. O. RANSFORD, M. A. MANSELL
}

\author{
From St Peter's Hospitals, London, and the Royal National Orthopaedic Hospital, Stanmore
}

\begin{abstract}
The surgical correction of scoliosis in adolescents involves considerable trauma to bone and muscle which, together with hypotensive anaesthesia, might be expected to compromise renal function. Our recent observation of acute renal failure in two such patients prompted a prospective study of renal function following 52 operations in $\mathbf{4 3}$ patients. Despite hypotension, blood loss, muscle damage and evidence of fat embolism, renal function was unaltered in all patients, and there was no impairment of spinal cord function. Careful attention was paid to the maintenance of circulating volume which is essential to protect renal perfusion.
\end{abstract}

The surgical treatment of scoliosis probably involves more trauma to muscle and bone than any other elective orthopaedic operation. The combination of induced peroperative hypotension (Youngman and Edgar 1985), myoglobinuria and fat embolism might be expected to compromise renal function and, indeed, one of us (MAM) has previously observed acute renal failure in two such patients. In order to determine whether renal failure is a significant risk in scoliosis operations with induced hypotension, a prospective study was undertaken to determine the effect on renal function. The study was approved by the Ethical Committees of the Institutes of Urology and Orthopaedics, and informed consent was obtained from all patients or their parents.

\section{PATIENTS AND METHODS}

Fifty-two consecutive operations in 43 patients were studied, nine patients undergoing a two-stage procedure (Youngman and Edgar 1985). There were 11 male patients and 32 female whose ages ranged from 12 to 25

P. B. Rylance, BSc, MRCP, Consultant Physician and Nephrologist Renal Unit, New Cross Hospital, Wolverhampton WV10 0QP, England.

F. Carli, MD, FFARCS, Anaesthetic Senior Registrar

S. E. McArthur, BSc, MSc, Biochemist

A. O. Ransford, FRCS, Consultant Orthopaedic Surgeon

Royal National Orthopaedic Hospital, Brockley Hill, Stanmore, Middlesex HA7 4LP, England

M. A. Mansell, MD, MRCP, Consultant Nephrologist

Renal Unit, St Peter's Hospital, Henrietta Street, London WC2A 2EX, England

(C) 1988 British Editorial Society of Bone and Joint Surgery

$0301-620 \mathrm{X} / 88 / 1001 \$ 2.00$

J Bone Joint Surg [Br] 1988;70-B:127-9. years (mean 15.8 years). Mean weight was $48.9 \mathrm{~kg}$ (range 31 to $83.5 \mathrm{~kg}$ ). Thirty-eight of the patients had adolescent idiopathic scoliosis, while in five the spinal deformity was secondary to neurological conditions. All patients had pre-operative plasma urea and creatinine values within the normal range. Respiratory function was assessed before operation.

Anaesthesia was induced with thiopentone, and muscle relaxation obtained with suxamethonium and $d$ tubocurarine. The patients were ventilated with a nitrous oxide/oxygen mixture together with halothane and an intravenous narcotic. They were then positioned either on one side for the anterior approach, or prone for posterior fusion. In the prone position a pelvic support and chest cushions or a Montreal mattress were used to minimise intra-abdominal pressure. Forty-three of the scoliosis operations were posterior spinal fusions. The maximum correction available was maintained by a Harrington rod implant and the distractive correction improved by multiple sublaminar wires. The posterior spinal structures over the instrumented area were prepared for bony fusion by excision of the posterior facet joints, removal of the spinous processes and decortication of the laminae. Bone used for grafting was obtained from the iliac crest. In nine patients, anterior spinal operations were performed, and consisted of radical disc and end-plate excision at five or six disc levels. In some patients an anterior Zielke implant was used.

Blood loss was measured by weighing the swabs and by suction volume. Somatosensory evoked potentials were recorded by an epidural electrode at the cephalad end of the operative field; the stimulus consisted of an electrical impulse to the posterior tibial nerve by means of a popliteal skin electrode on each leg. Intra- 
operatively, dextrose-saline was infused $(4 \mathrm{ml} / \mathrm{kg} / \mathrm{h})$ and blood was given to replace losses. Induced hypotension was employed during posterior fusion using an infusion of trimetaphan together with intermittent positive pressure ventilation. Intra-arterial blood pressure was measured and maintained at a systolic level of 60 to $70 \mathrm{mmHg}$. Prophylactic intramuscular cephradine was given before and in two doses after operation. Postoperatively dextrose-saline was given at a rate of $40 \mathrm{ml} / \mathrm{kg} / 24 \mathrm{~h}$ (mean $2000 \mathrm{ml} / 24 \mathrm{~h}$, providing $60 \mathrm{mmol} \mathrm{Na} / 24 \mathrm{~h}$ ).

Blood samples and 24-hour urine collections were taken before operation (Day 0 ) and for four consecutive days after operation (Days 1 to 4). Daily blood samples were assayed for sodium, potassium, bicarbonate, urea, creatinine, uric acid (by the ultraviolet uricase method), creatinine kinase (CK) (using the ultraviolet acetyl cysteine activated system) and CK-MB (cardiac muscle) isoenzyme (by immunoassay); 24-hour urine excretion of sodium, potassium, urea and creatinine was measured. Urine from the first postoperative day was examined for the presence of myoglobin by radio-immunoassay using a double-antibody technique. In addition, daily specimens of urine were examined for fat droplets using Red O stain and tested for blood with Multistix Test Strips. Results are expressed as means with standard deviation, and comparison was made with pre-operative values using paired Student's $t$-tests.

\section{RESULTS}

Blood pressure was maintained at low levels during the operation in all patients, the mean lowest systolic pressure being $65 \mathrm{mmHg}$, range 40 to $100 \mathrm{mmHg}$. Mean peroperative blood loss was $725 \mathrm{ml}$ (range 120 to $3200 \mathrm{ml}$ ) and, despite peroperative blood replacement of $641 \mathrm{ml}(0$ to $2900 \mathrm{ml})$ and postoperative transfusion where indicated, the mean fall of haemoglobin concentration during the postoperative period was $2.03 \mathrm{~g} / \mathrm{dl}$ (maximum fall $8.4 \mathrm{~g}$ ). Postoperatively all patients became pyrexial (mean maximum temperature being $38.2^{\circ} \mathrm{C}$, range $37.2^{\circ}$ to $40.2^{\circ} \mathrm{C}$ ) although there was no clinical evidence of infection and all urine cultures were negative. No patient had any neurological complications as a result of the operation.

Biochemical changes are shown in Figure 1. Renal function was preserved after all operations and in no patient did plasma creatinine rise above the upper limit of the normal range; its mean level fell progressively over the first four days. This was associated with an increased urinary creatinine excretion, the maximum being $21.4 \mathrm{mmol} / 24 \mathrm{~h}$; in nine patients creatinine clearance increased to greater than $150 \mathrm{ml} / \mathrm{min}$. Muscle breakdown was reflected by a marked elevation of creatinine kinase on Day 1 (range 321 to $7090 \mathrm{iu} / \mathrm{l}$ ), which continued to Day 4. In age-matched patients undergoing osteotomy operations, creatinine kinase on the first postoperative day ranged from 170 to $706 \mathrm{iu} / 1$ (mean $469 \mathrm{iu} / \mathrm{l})$. There

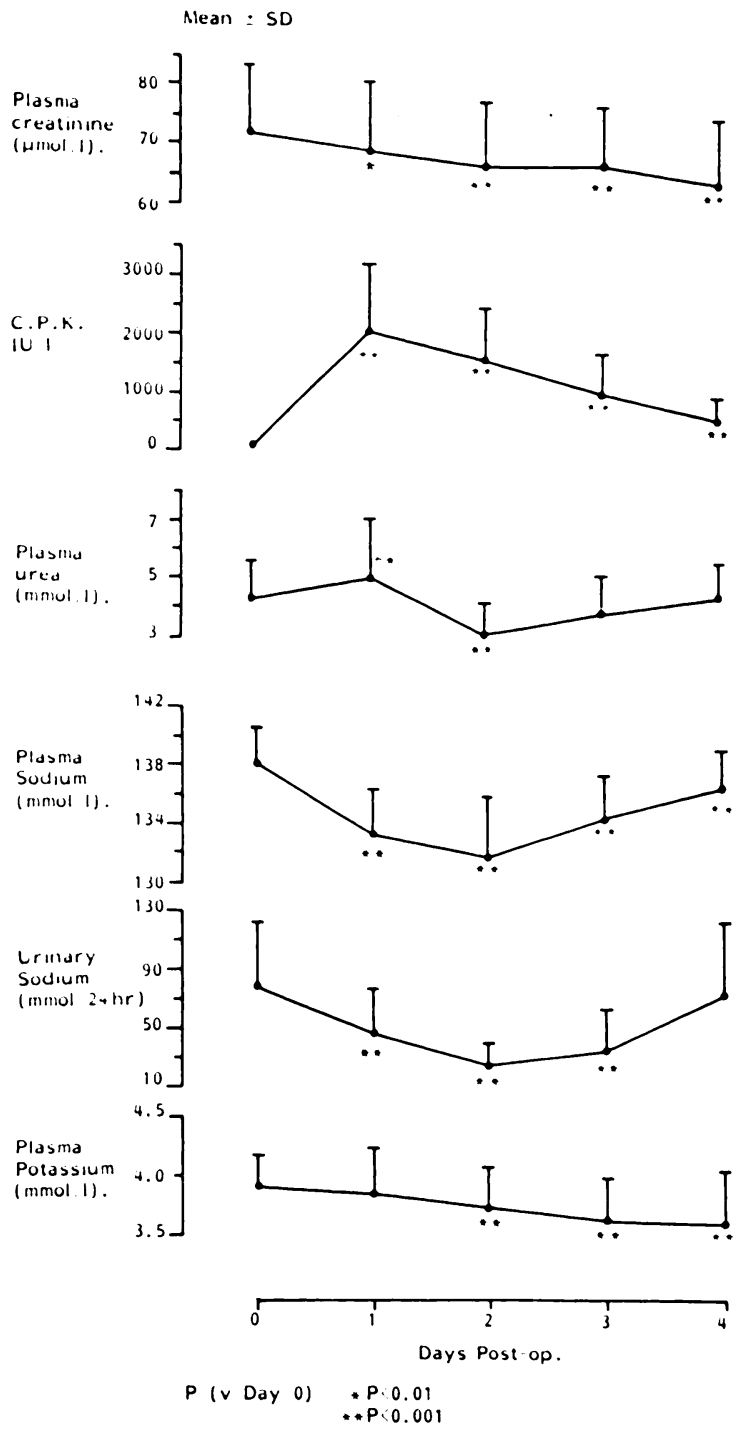

Fig. 1

Plasma and urinary biochemistry pre-operatively (Day 0 ) and for four days after scoliosis surgery. CPK, creatinine (phospho)kinase.

was no elevation of creatinine kinase from cardiac muscle in any scoliosis patient, indicating that the rise of creatinine kinase was purely from skeletal muscle. Despite this no patient had myoglobin detected in the urine on the first day. Plasma urea rose slightly on Day 1, fell on Day 2 and returned to pre-operative levels by Day 4. This was associated with a progressive increase of urinary urea excretion, which was $204 \pm 94 \mathrm{mmol} / 24 \mathrm{~h}$ pre-operatively, and $312 \pm 134 \mathrm{mmol} / 24 \mathrm{~h}$ on Day 4 $(p<0.005)$.

Hyponatraemia (plasma sodium less than $135 \mathrm{mmol} / \mathrm{l}$ ) occurred after 45 of the 52 operations $(86.5 \%)$. Maximum fall of plasma sodium occurred on Day 2, then recovered to within normal limits by Day 4, the lowest level observed being $120 \mathrm{mmol} / \mathrm{l}$. Urinary sodium fell postoperatively and in 19 cases $(36.5 \%)$ it was less than $10 \mathrm{mmol} / \mathrm{day}$; it also returned to pre-operative values by Day 4 . There was a small, but significant fall of 
plasma potassium by Day 2, though the mean values remained within normal limits: in 31 cases $(60 \%)$ hypokalaemia occurred (less than $3.5 \mathrm{mmol} / \mathrm{l}$ ). Plasma bicarbonate levels did not alter significantly. After eight of the operations $(15 \%)$ plasma uric acid fell on Day 4 to $100 \mu \mathrm{mol} / \mathrm{l}$ or less, although there was no consistent pattern of urinary urate excretion.

Fat droplets were seen in the urine on Day 1 or Day 2 after $21(40 \%)$ of the operations.

\section{DISCUSSION}

The operative correction of scoliosis is one of the most tissue-destructive forms of non-ablative surgery now practised. The technique of induced peroperative hypotension has not, as yet, gained general acceptance because of concern about decreased perfusion of kidneys and spinal cord, although our experience shows that this operation is notably free from serious complications (Youngman and Edgar 1985). The safety of the operation in our hands is, perhaps, even more striking, given that the degree of hypotension was considerably greater than that used by Patel and co-workers (1985), and mean blood loss in our patients was $50 \%$ less. This prospective study has shown that renal function is preserved.

Muscle trauma, indicated by the rise of creatinine kinase, was much greater than in patients of similar age undergoing osteotomy operations, although considerably less than in frank rhabdomyolosis, where creatinine kinase levels may rise to several hundred thousand. The failure to detect myoglobin in the urine by a sensitive radio-immunoassay, despite evidence of muscle damage reflected in high creatinine kinase levels, is surprising. The combination of increased urinary creatinine with a slight fall in plasma creatinine suggests that glomerular filtration rate is actually increased, although expansion of the circulating volume by dilution may also have occurred. The increased urinary urea reflects the postoperative catabolic state of these patients, with negative nitrogen balance.

Several factors are relevant to the postoperative hyponatraemia seen in this study. In all major operations sodium and water retention by the kidney results from increased cortisol levels (Le Quesne, Cochrane and Fieldman 1985) and stimulation of renin and vasopressin release by hypovolaemia (Cochrane et al. 1981). Additionally dextrose-saline infusion probably is inadequate to correct the deficit of total body sodium, and results in dilutional hyponatraemia. An increase of sodium replacement would seem justifiable, perhaps as plasma rather than in crystalloid form (Twigley and Hillman 1985). Similarly, the development of hypokalaemia would make potassium supplements appropriate. The fall of plasma uric acid is difficult to explain, though it probably reflects alterations in tubular handling of urate.

The appearance of fat droplets in the urine of $40 \%$ of the cases may reflect operative trauma but could also indicate that fat embolism has occurred via the pulmonary circulation. Deterioration of pulmonary function occurs following correction of scoliosis, which is thought to be largely due to restriction of movement of the thoracic cage, although fat embolism in the pulmonary capillaries may also occur.

Spinal cord function may be impaired by either fall in blood pressure (Grundy, Nash and Brown 1981) or by occlusion of the arterial blood supply during correction of scoliosis. Somatosensory evoked potentials were monitored throughout surgery and no electrophysiological or clinical neurological impairment occurred. Hypotension was induced by peripheral vasodilatation with trimetaphan, which is a potent sympathetic ganglion blocker with a short plasma half-life, is non-toxic and does not produce rebound hypertension. Autoregulatory mechanisms protect blood flow to the central nervous system despite systemic hypotension.

This study shows that in operations to correct scoliosis in adolescents, the technique of induced hypotension to reduce operative blood loss does not compromise renal function despite being combined with trauma to bone and muscle, blood loss and fat embolism. The maintenance of circulatory volume by avoiding sodium and water depletion is essential to prevent renal failure developing as a result of decreased renal perfusion.

We would like to acknowledge the contribution of the surgeons who allowed us to study their patients and who performed many of the operations (P. J. Webb, T. R. Morley, M. A. Edgar), the anaesthetists (Dr P. M. E. Youngman, Dr L. Girgis, Dr E. Grundy), Dr G. A. Rose (Consultant Chemical Pathologist) and the biochemistry and microbiology technicians.

\section{REFERENCES}

Cochrane JPS, Forsling ML, Gow NM, Le Quesne LP. Arginine vasopressin release following surgical operations. Br J Surg $1981 ; 68: 209-13$.

Grundy BL, Nash CL Jr, Brown RH. Arterial pressure manipulation alters spinal cord function during correction of scoliosis. Anesthesiology $1981 ; 54: 249-53$.

Le Quesne LP, Cochrane JPS, Fieldman NR. Fluid and electrolyte disturbances after trauma: the role of adrenocortical and pituitary hormones. Br Med Bull 1985;41:212-7.

Patel NJ, Patel BS, Paskin S, Laufer S. Induced moderate hypotensive anaesthesia for spinal fusion and Harrington-rod instrumentation. $J$ Bone Joint Surg [Am] 1985;67-A:1384-7.

Twigley AJ, Hillman KM. The end of the crystalloid era? A new approach to peri-operative fluid administration. Anaesthesia $1985 ; 40: 860-71$.

Youngman PME, Edgar MA. Posterior spinal fusion and instrumentation in the treatment of adolescent idiopathic scoliosis. Ann R Coll Surg Engl 1985;67:313-7. 